\title{
GIANT-CELL TUMOUR OF BONE
}

\section{An Analysis of Fifty-two Cases}

\author{
P. J. McGrath, Pymble, New South Wales, Australia \\ From the Bristol Bone Tumour Registry, Bristol, England
}

Giant-cell tumours of bone are rare. As a consequence there have been few reports of large series. Recently Goldenberg, Campbell and Bonfiglio (1970) described 218 cases from various centres in the United States of America, and Dahlin, Cupps and Johnson (1970) 195 cases from the Mayo Clinic. In the British literature smaller series have been reported by Ellis (1949), Prossor (1949), Windeyer and Woodyatt (1949), Thomson and Turner-Warwick (1955), Eyre-Brook (1956), Golding (1966) and Wearne (1968).

The purpose of this paper is to describe fifty-two cases of giant-cell tumour from the records of the Bristol Bone Tumour Registry, with particular reference to the results of treatment. That many methods are currently used reflects the considerable confusion that still exists. From a study of the results, certain recommendations will be made regarding management.

\section{MATERIAL}

Since the Bristol Bone Tumour Registry was founded in 1946, seventy cases of giant-cell tumour satisfying the criteria of Jaffe, Lichtenstein and Portis (1940) have been recorded. The cases have come not only from the city of Bristol and surrounding districts, but also from other parts of the United Kingdom and from overseas.

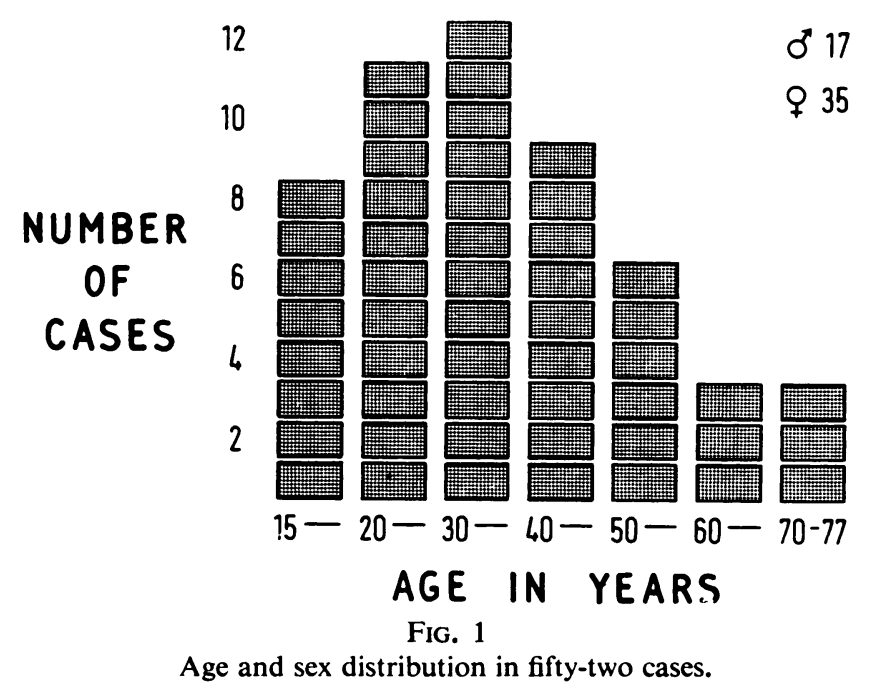

A careful review of the material led to certain cases being excluded, namely one with metastases at the time of diagnosis, those with a follow-up period of less than two years, others inadequately documented, and all tumours of jaws. Jaffe (1953) considered that the giant-cell tumour was seldom encountered in a jaw bone. 
As a result of these exclusions the number was reduced to fifty-two. The patients were first seen between 1943 and 1968, the shortest follow-up being two years and the average eleven years. All but six patients were observed for at least five years. Of these six, three are still alive and three have died, two from the effects of tumour and one from myocardial infarction.

Follow-up information was obtained from the hospital records, from personal examination of patients by their doctor or by the author, or by writing to the patients, their doctors or their relatives.

\section{FINDINGS}

Incidence-Each year, approximately one new case was reported per million population of the city of Bristol and surrounding districts. This represented 3 per cent of all primary malignant tumours of bone in this area, including myeloma.

Age and sex-The age distribution is shown in Figure 1. The youngest patient was fifteen and the oldest seventy-seven years, the highest incidence being in the third and fourth decades. Eight patients ( 15 per cent) were under twenty, seven being girls. There was a marked female predominance in this series. Location-The distribution of the fifty-five tumours in fifty-two patients is shown in Figure 2. Forty-eight ( 87 per cent) were situated near the ends of long bones, the most frequent sites being the lower end of the femur, the upper end of the tibia and the upper end of the femur. Thirty-one (56 per cent) occurred around the knee. One patient presented with four tumours, in the lower end of radius, lower end of ulna, metacarpal head and base of proximal phalanx. Hyperparathyroidism was excluded by repeated biochemical tests, and this was thought to be a true multifocal occurrence.

\section{SYMPTOMS AND SIGNS}

Pain or pain and swelling were the commonest presenting symptoms. Seven patients had pathological fractures when first seen, of whom three had had no preceding symptoms. There was a history of injury in eight patients. The duration of the symptoms was between two weeks and four years, more than one-third of the patients having had complaints for longer than six months.

Three patients with lesions around the knee had been treated for some disorder of that joint before the correct diagnosis was made. One sacral tumour caused unilateral sciatica, the other cauda equina symptoms. A tumour in the basisphenoid produced frontal headaches followed by visual defects.

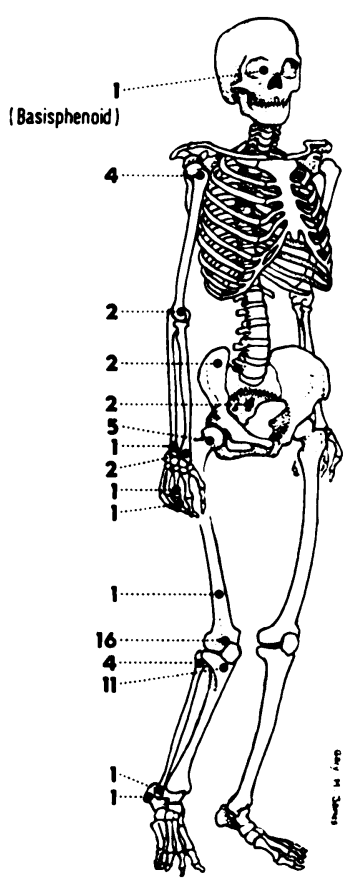

Fig. 2

The distribution of fiftyfive lesions in fifty-two patients.

\section{RADIOGRAPHIC APPEARANCE}

All patients were skeletally mature at the time of diagnosis. The typical tumours showed as expanded lytic lesions in the ends of long bones, occupying the epiphysial and metaphysial regions. Usually eccentrically placed, they often showed perforation of the cortex or articular margin, even when clinical features of fracture were absent.

One tumour was confined to the shaft of the femur; another in the lower femur was situated almost completely above the epiphysial region and subsequently extended up the shaft (Figs. 3 to 5). Histologically both were malignant. 


\section{PATHOLOGY}

Macroscopic features-The tumours were most often described as consisting of soft gelatinous material, reddish-grey in colour and containing yellow or red areas. They were only occasionally firm in consistency.

Microscopic features-Although attempts were made to grade the degree of aggressiveness of the earlier tumours, this was abandoned later and the tumours were designated as typical or malignant. The term benign was not used deliberately because tumours that have all the histological features of innocence might at any time act in an aggressive fashion, and occasionally metastasise (Finch and Gleave 1926, Dyke 1931, Murphy and Ackerman 1956, Jewell and Bush 1964).

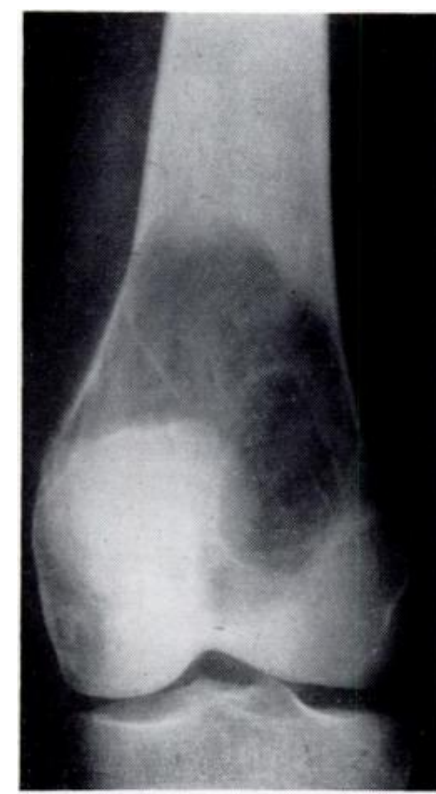

FIG. 3

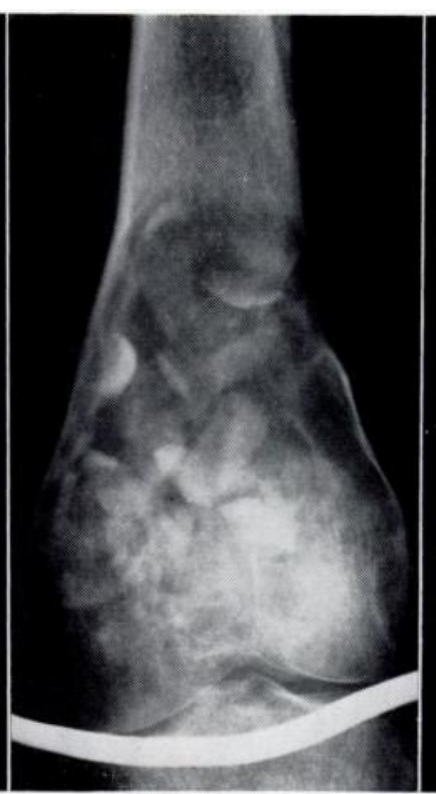

FIG. 4

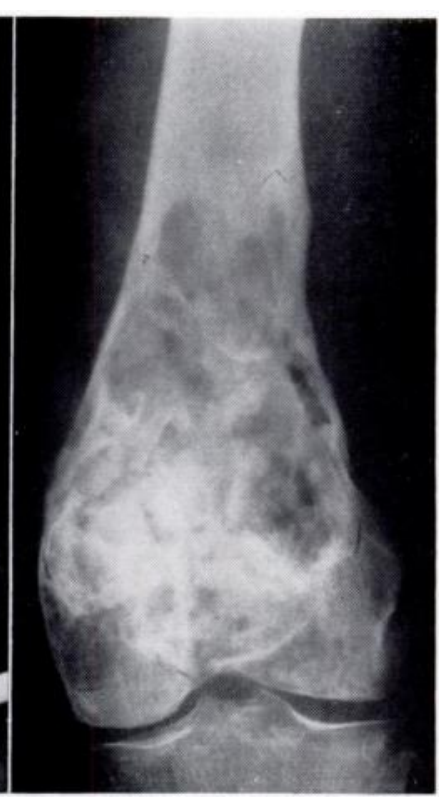

FIG. 5

Case 6. Figure 3-The original radiograph of a malignant tumour in the lower femur. Figure 4A radiograph showing the proximal extension three months after curettage and graft. Figure 5 A radiograph showing further extension twenty months after curettage and graft, and before amputation.

The typical tumour had a vascular stroma of plump polyhedral cells diffusely interspersed with multinucleated giant cells of varying numbers and size. There was little pleomorphism in either the stroma or the giant cells, the nuclei of these two types of cells being similar in size and shape.

\section{MALIGNANT TUMOURS}

Much confusion exists as to what constitutes a malignant tumour on histological grounds. Dahlin et al. (1970) stated that to qualify as a malignant giant-cell tumour, a tumour must have histological evidence of the benign counterpart in the lesion under study or in the material removed previously from the same area.

All the malignant tumours satisfied this criterion, with the exception of one on which no biopsy was done, the diagnosis being based on clinical and radiographic evidence.

Malignant tumours were divided into three types: 1) primary, in which the tumour was malignant from the outset; 2) evolutionary, in which a typical tumour progressed to a malignant form within a short period; and 3) secondary, in which a typical tumour underwent sarcomatous change after a relatively long symptom-free period, usually after irradiation. 


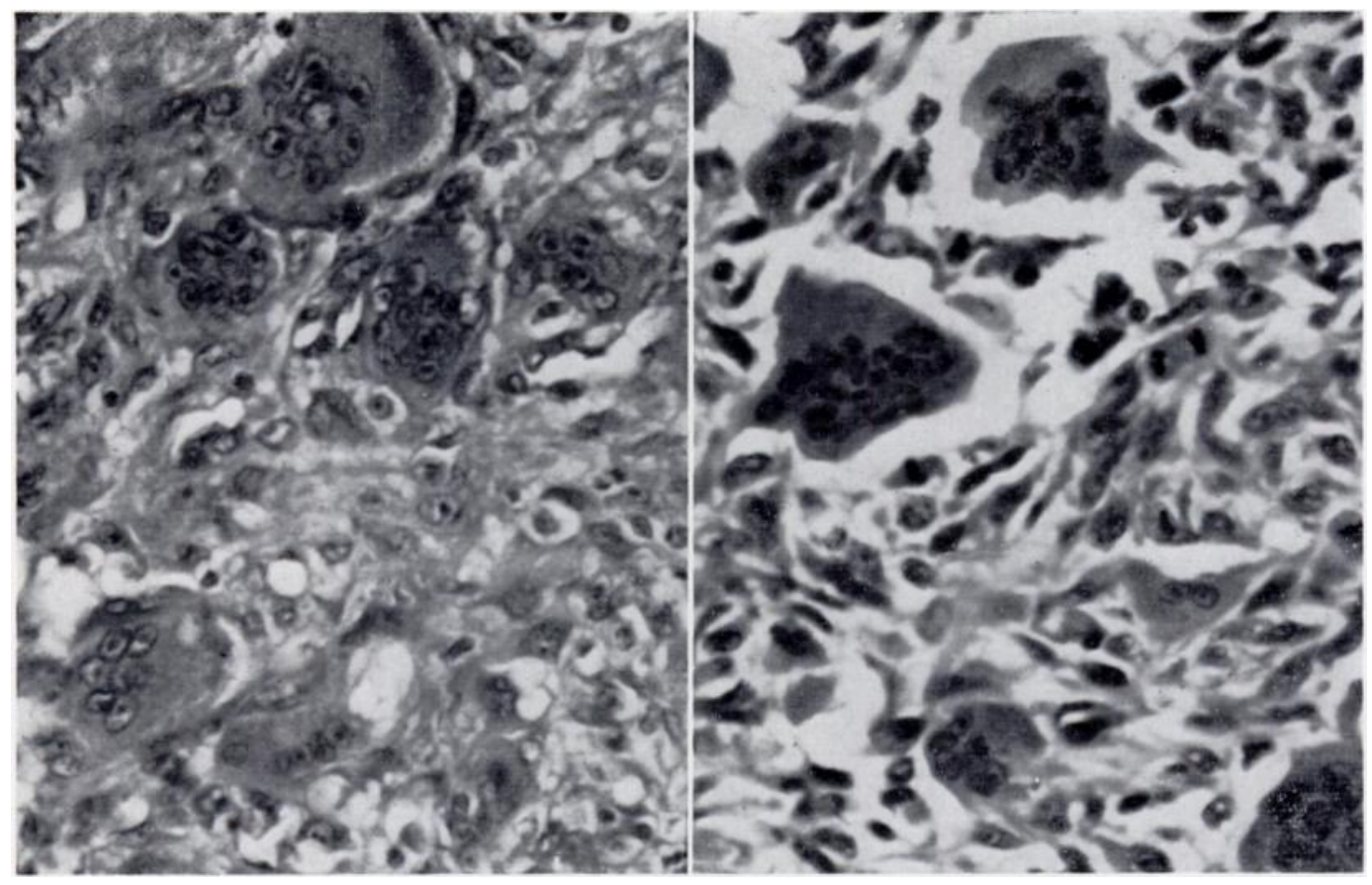

FIG. 6

FIG. 7

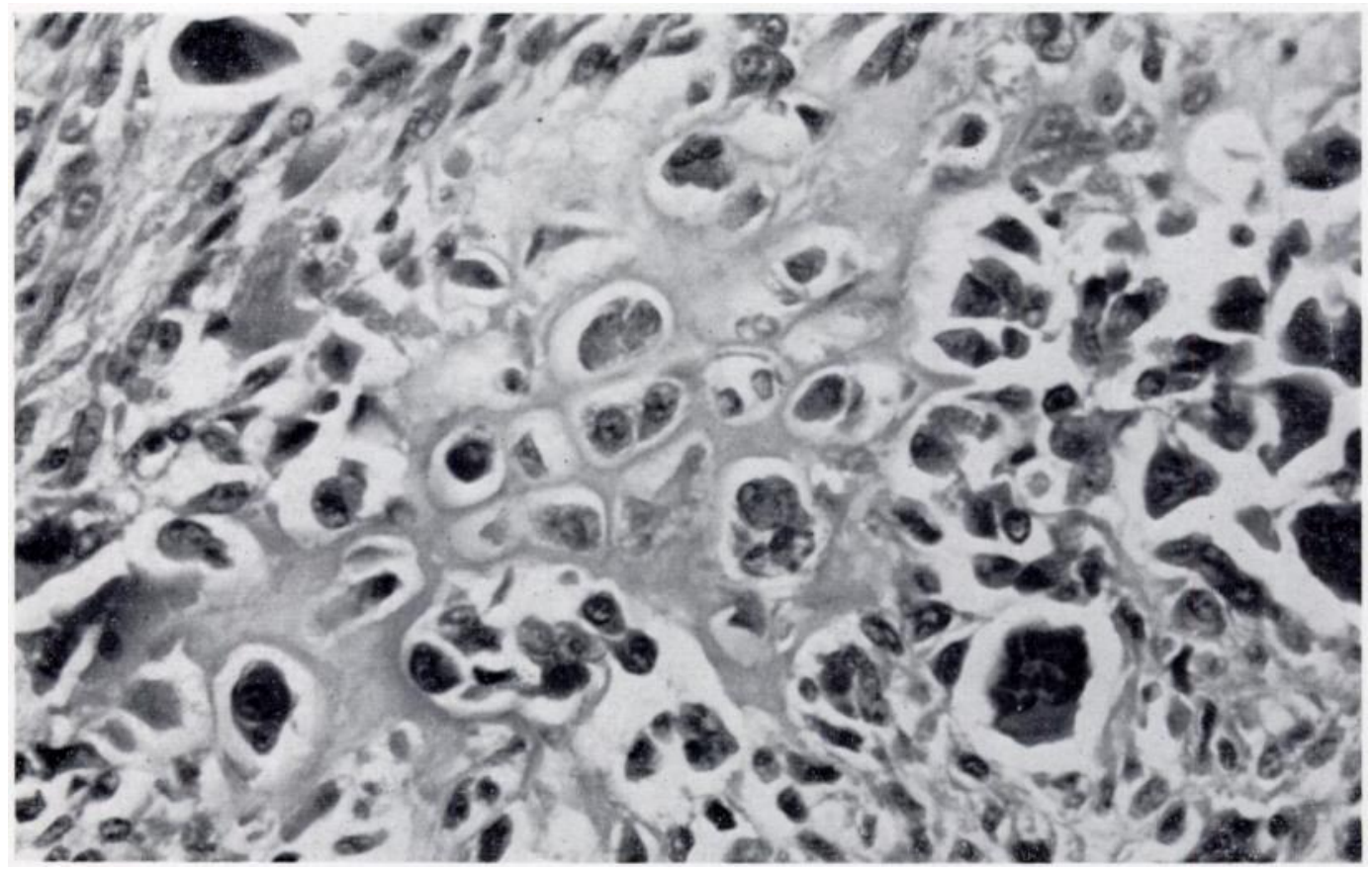

FIG. 8

Case 7. Figure 6-Photomicrograph of a giant-cell tumour of the femur. In this field the appearances are not unduly ominous. (Haematoxylin and eosin, $\times 400$.) Figure 7-Another field of the same tumour. Note the pleomorphism of the stroma cells and the mitotic figures. (Haematoxylin and eosin, $\times 400$.) Figure 8-Here the pleomorphic stroma cells show differentiation to osteoblasts with an area of chondro-osteoidal matrix. (Haematoxylin and eosin, $\times 400$.) 
In this series there were three cases of primary, one of evolutionary and four of secondary malignancy (Table III).

Two of the primary malignant tumours were in unusual positions in the femur. The tumour confined completely to the shaft contained areas showing a marked tendency to osteoblastic activity, as well as areas of conventional giant-cell tumour (Figs. 6 to 8).

\section{TREATMENT}

This will be considered under two headings: primary and secondary - that is, of recurrences and any subsequent complications. Recurrence is defined as radiological or clinical evidence of renewed activity in the tumour, more than three months after primary treatment.

TABLE I

Primary TReatment

\begin{tabular}{|c|c|c|c|c|c|}
\hline \multirow{2}{*}{ Type of treatment } & \multirow{2}{*}{$\begin{array}{l}\text { Total } \\
\text { cases }\end{array}$} & \multicolumn{4}{|c|}{ Recurrences } \\
\hline & & $\begin{array}{l}\text { Less than } \\
5 \text { years }\end{array}$ & Late & Total & Per cent \\
\hline Curettage + graft . & 20 & 9* & 0 & 9 & 45 \\
\hline Curettage + radiotherapy & 5 & 0 & 1 & $1(\mathrm{MC})$ & 20 \\
\hline Curettage + graft + radiotherapy & 2 & 1 & 0 & 1 & 50 \\
\hline Local excision & 1 & 0 & 0 & 0 & 0 \\
\hline Local excision + radiotherapy & 1 & 0 & 0 & 0 & 0 \\
\hline Resection . & 7 & 0 & 0 & 0 & 0 \\
\hline Resection + radiotherapy. & 1 & 0 & $\mathbf{0}$ & 0 & 0 \\
\hline Radiotherapy alone & 12 & 2 & 4 & $6(4 \mathrm{MC})$ & 50 \\
\hline Amputation & 3 & $\mathbf{0}$ & 0 & 0 & 0 \\
\hline Total . & 52 & 12 & 5 & $17(5 \mathrm{MC})$ & 33 \\
\hline
\end{tabular}

* Average period 2 years. MC: Malignant change of previously typical tumour.

\section{PRIMARY TREATMENT}

Nine different plans of treatment were used initially. These were: curettage and graft, curettage and radiotherapy, curettage and graft and radiotherapy, excision, excision and radiotherapy, resection, resection and radiotherapy, radiotherapy alone, and amputation. The overall results of primary treatment are summarised in Table $I$.

Curettage and graft-Nearly two-fifths of the patients were treated by careful evacuation of the tumour by curettage and packing the cavity with iliac cancellous bone, at times reinforced with iliac or tibial cortex, and supplemented once by heterogenous bone. Some cavities had zinc chloride solution applied to the walls before it was filled with chips. The recurrence rate of 45 per cent with this treatment was a little worse than that of Goldenberg et al. (1970) 40 per cent, and of Dahlin et al. (1970)-34 per cent. However, those cases in which the operation notes indicated that great care was taken, had much better results than the others, where either the operation notes were scanty or did not indicate that thorough tumour evacuation was possible. Seven of the nine recurrences appeared within the first two years, and none was a malignant change of a previously typical tumour. 


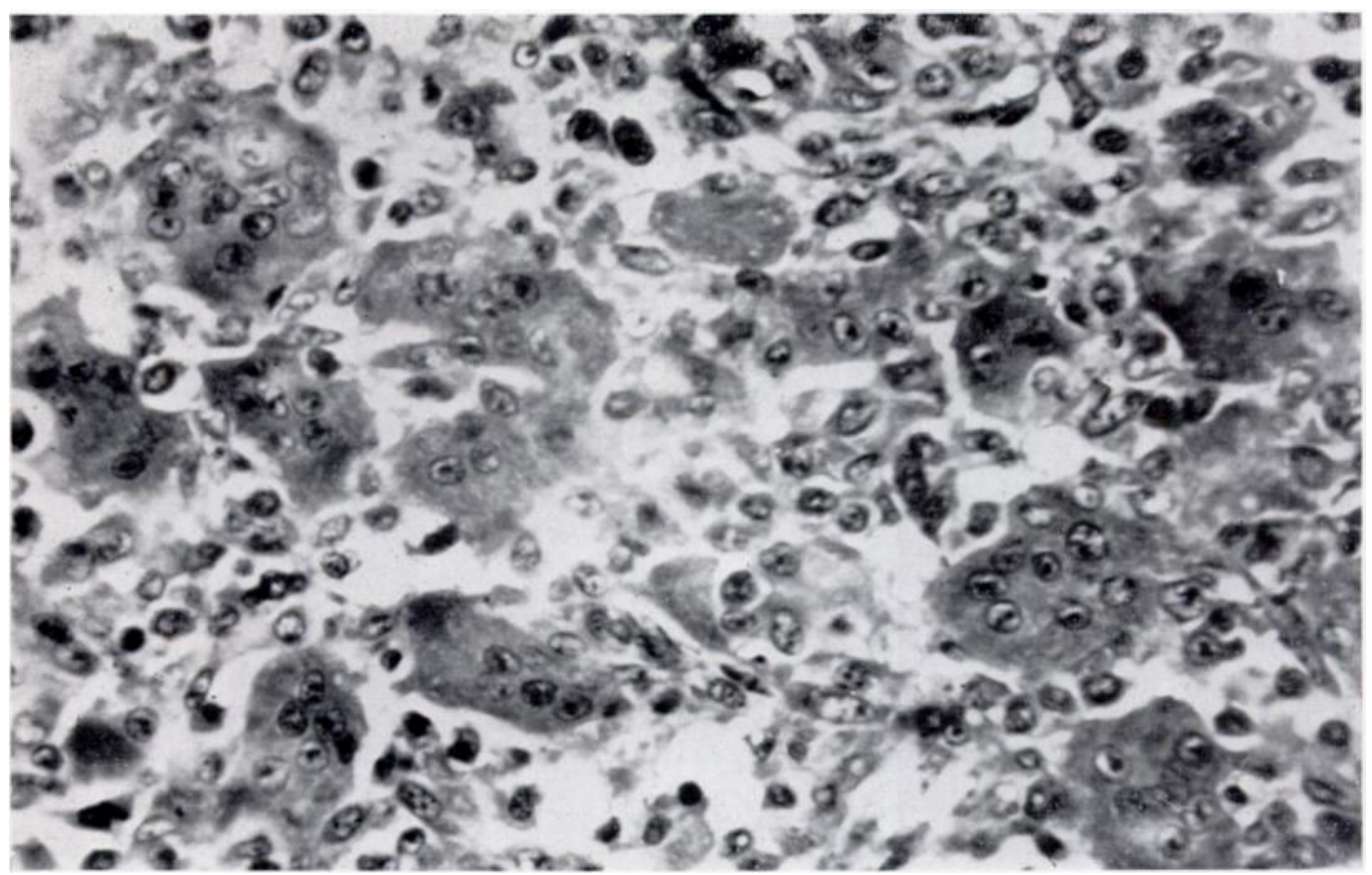

FIG. 9

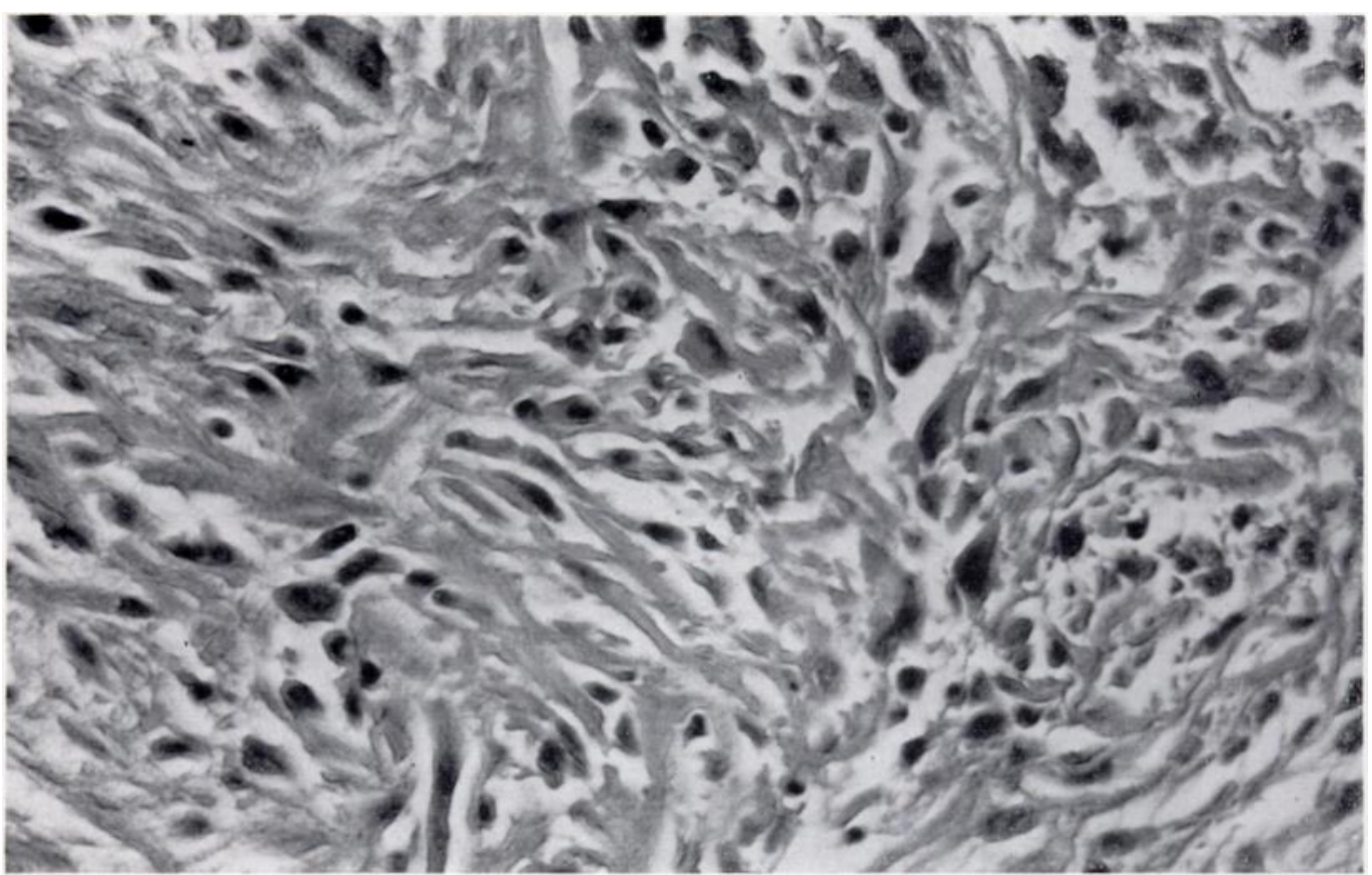

FIG. 10

Case 4. Figure 9-A photomicrograph of the original giant-cell tumour of the tibia which shows the conventional morphology. (Haematoxylin and eosin, $\times 400$.) Figure 10-There is now pleomorphic fibrosarcoma in the recurrent tumour in which much coarse collagen is seen throughout. (Haematoxylin and eosin, $\times 400$.)

VOL. 54 B, NO. 2, MAY 1972 
Curettage and radiotherapy-Of the five cases, one recurred as a fibrosarcoma seventeen years after initial treatment (Figs. 9 and 10) and above-knee amputation was successful.

Curettage and graft and radiotherapy-In one of the two patients a pathological fracture occurred immediately after a second course of deep x-ray therapy (2,600 r and 2,500 r) (Figs. 11 to 14). Thereafter curettage showed viable tumour cells. The other pattent had a malignant tumour in the lower femur. Curettage and inadequate bone grafting, in which the chips did not fill the cavity, was followed by rapid radiographic extension. The patient then had a course of $5,800 \mathrm{r}$ of deep x-ray, but the limb was amputated eighteen months later, as radiographs revealed further tumour growth in the femur (Figs. 3 to 5).

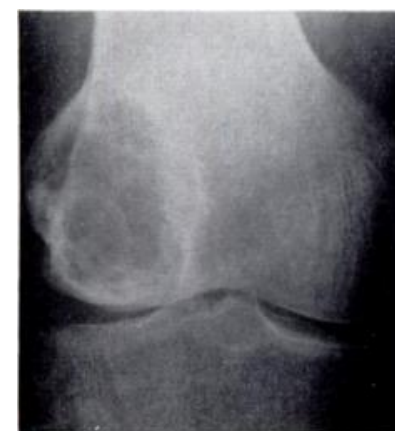

Fig. 11

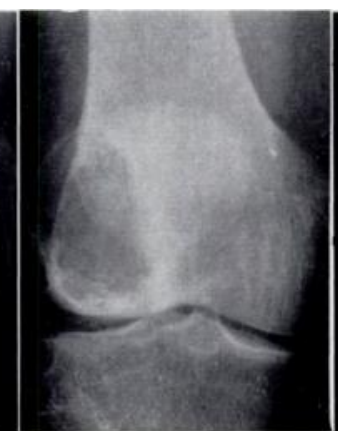

FIG. 12

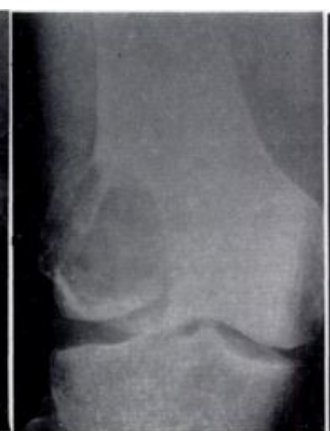

FIG. 13

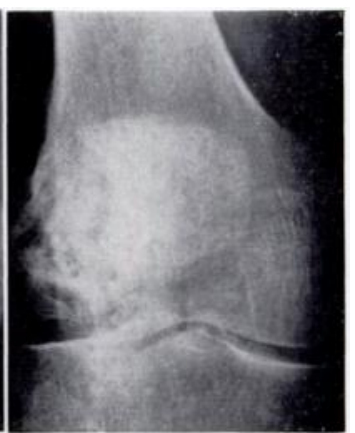

FIG. 14

Case 9. Figure 11-A radiograph taken in October 1949, four months after a course of radiotherapy. Figure 12-A radiograph in May 1950, immediately after a second course of radiotherapy. Note the thinned cortex and bone destruction. Figure 13-A radiograph taken three days later showing a pathological fracture. Figure 14-A radiograph taken fourteen years after curettage and graft, showing incorporation of the graft.

Excision-This was defined as the piecemeal removal of the tumour and differed from curettage in that some of the surrounding bone was also removed. Both the patients, one of whom had radiotherapy as well, were free from recurrences.

Cautery-Of the twenty-nine tumours treated by curettage and excision, the cavities of eight were cauterised by chemical or thermal means, with no recurrences. Of the remaining twentyone, for which there was no record of cautery, there were eleven recurrences.

Resection-This was defined as the en bloc removal of the tumour with its surrounding bone shell and periosteum, and a variable amount of soft tissue. It was used for all five tumours of the fibula, one in the ilium, one in the upper end and one in the lower end of the femur. A long stem Moore prosthesis was used to reconstruct the upper end of the femur. After resection of the lower femoral tumour the knee was arthrodesed by reversing the upper end of the tibia and fixation with a Küntscher nail (Figs. 15 and 16). There were no recurrences at an average of nine years after treatment.

Radiotherapy-Radiotherapy, either as 250 kilovolt deep x-rays or cobalt, was used as primary treatment for twelve tumours of which eight were in long bones, two in the sacrum, and one each in the ilium and sphenoid. Of these, six recurred ( 50 per cent), four being malignant recurrences of previously typical tumours. One appeared a year after primary treatment and is an example of evolutionary malignancy (Figs. 17 to 19), whereas the other three recurred eight, twelve and thirteen years after treatment. Four of the recurrences, including two malignant changes, appeared in long bones, in sites accessible to surgical treatment. The other malignant recurrences were in the sacrum. The dosage varied from 3,000 $r$ to $9,500 \mathrm{r}$ given in one, two or three courses over a period of up to eighteen months. There was no relationship between the dose and course, and the incidence of typical or malignant recurrences. Amputation-All three cases initially were thought to be malignant on clinical, radiographic and histological evidence. Subsequent review suggested that malignancy was questionable in each case. 


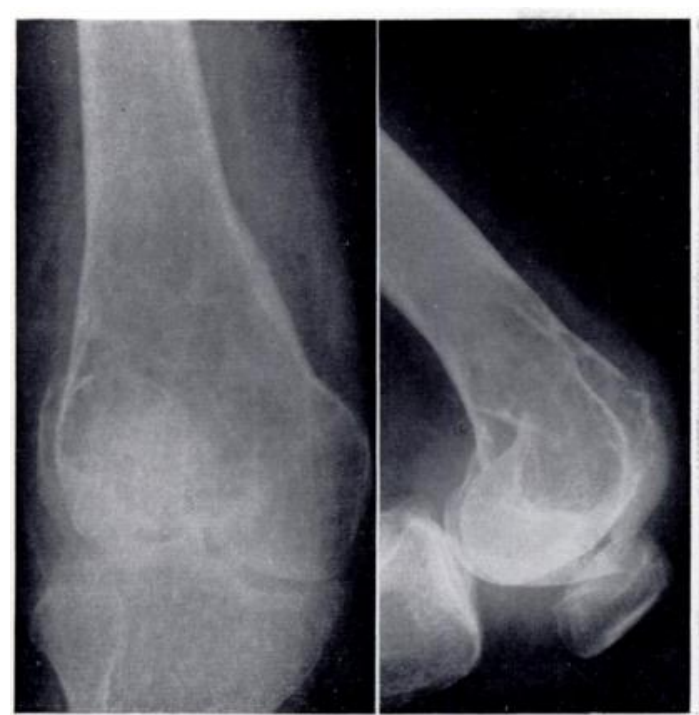

Fig. 15

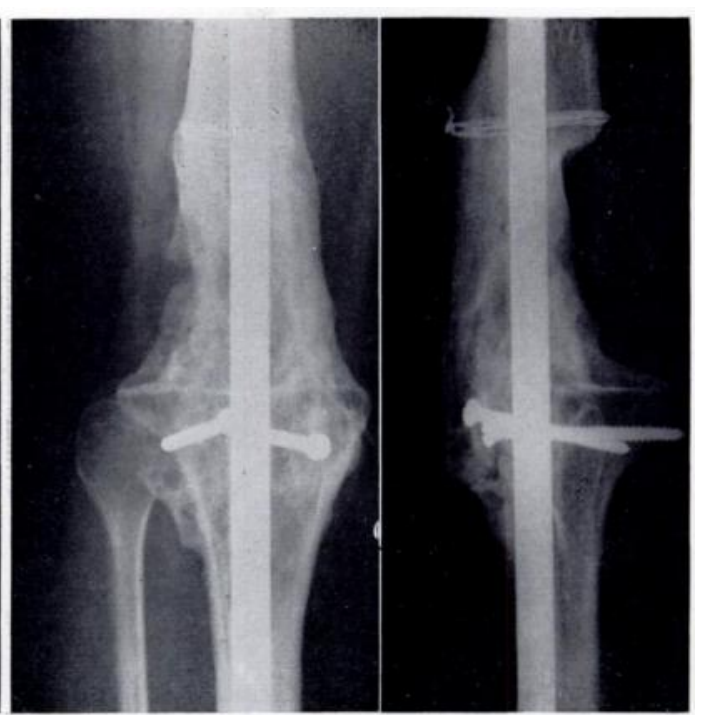

Fig. 16

Case 10. Figure 15-Antero-posterior and lateral radiographs of the lower end of the femur showing a large tumour with pathological fractures. Figure 16-Antero-posterior and lateral radiographs three years after resection of tumour and arthrodesis of knee.

\section{SECONDARY TREATMENT}

The three methods used locally were resection, radiotherapy and amputation, the results of which are summarised in Table II. Block dissection of glands, left dorsal lobectomy, radiotherapy to the chest and pelvis, and chemotherapy were used to treat metastases.

Resection-In the multifocal case there was a recurrence in the lower end of the ulna five years after deep x-ray therapy. The lower end of the ulna was resected and a biopsy taken from the adjacent radius; both contained viable tumour cells.

Radiotherapy-The initial treatment in one case was by radiotherapy and in four by curettage and graft.

TABLE II

SeCONDARY TREATMENT

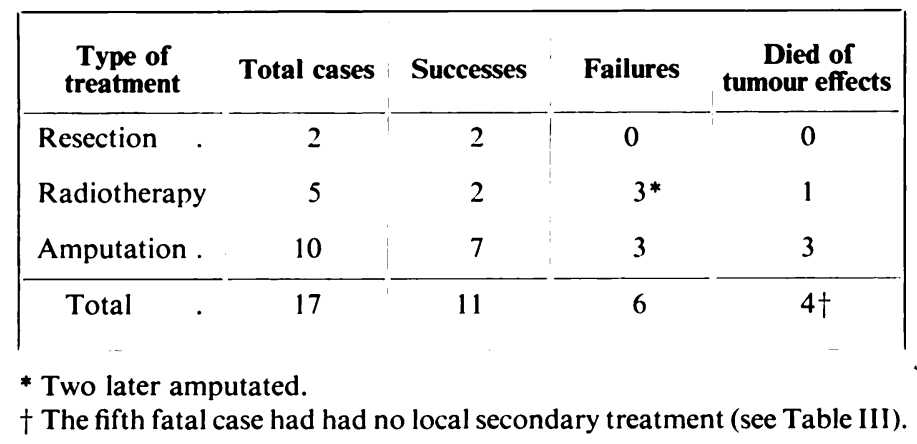

Amputation-This was used for four cases treated by radiotherapy, four treated by curettage and graft, one by curettage and radiotherapy and one by curettage, grafting and radiotherapy.

Resection and amputation dealt effectively with typical recurrences. Malignant recurrences, treated either by radiotherapy or amputation, had a poor prognosis. The features of the eight malignant tumours are summarised in Table III.

VOL. 54 B, NO. 2, MAY 1972 


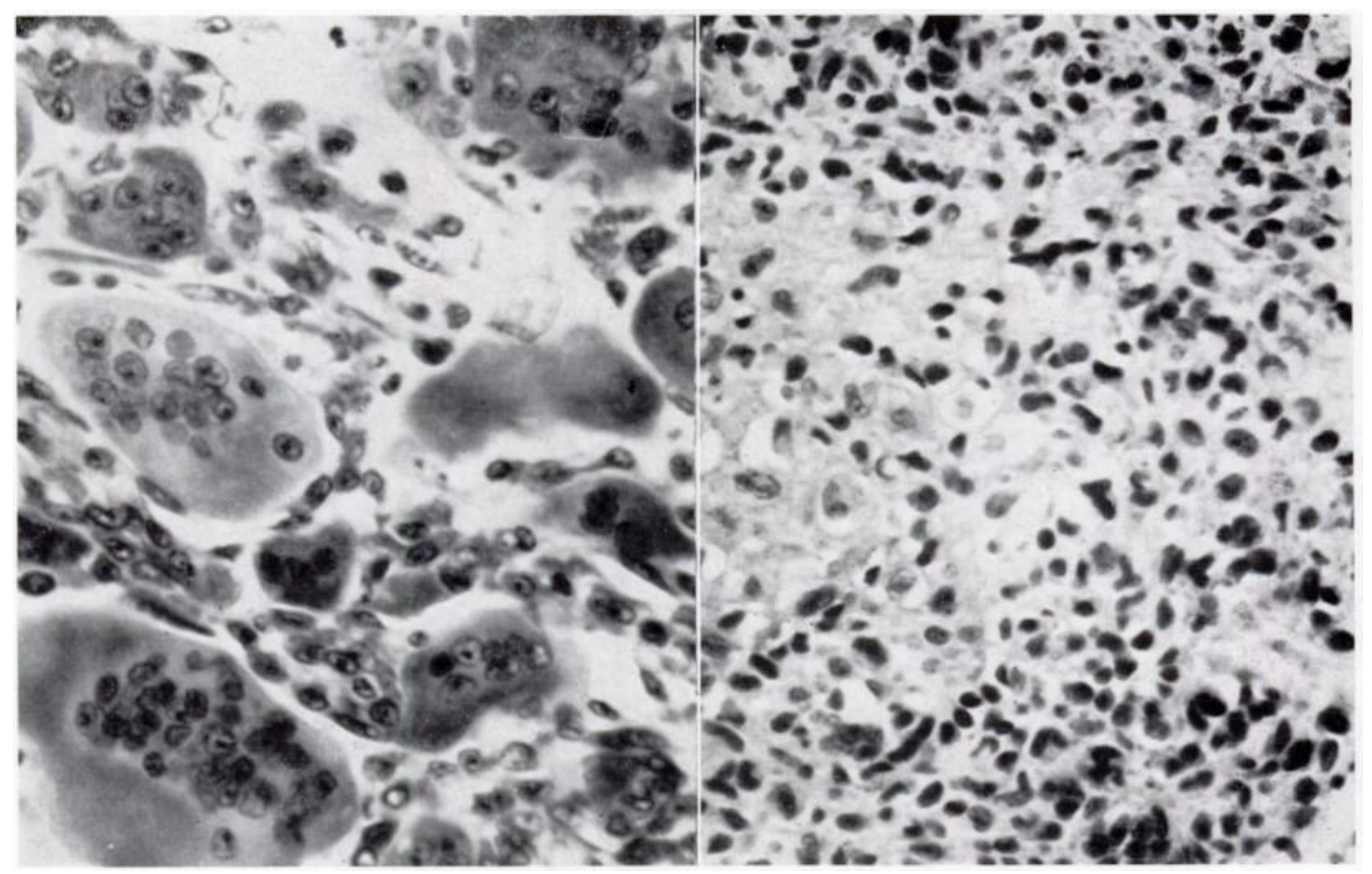

FIG. 17

FIG. 18

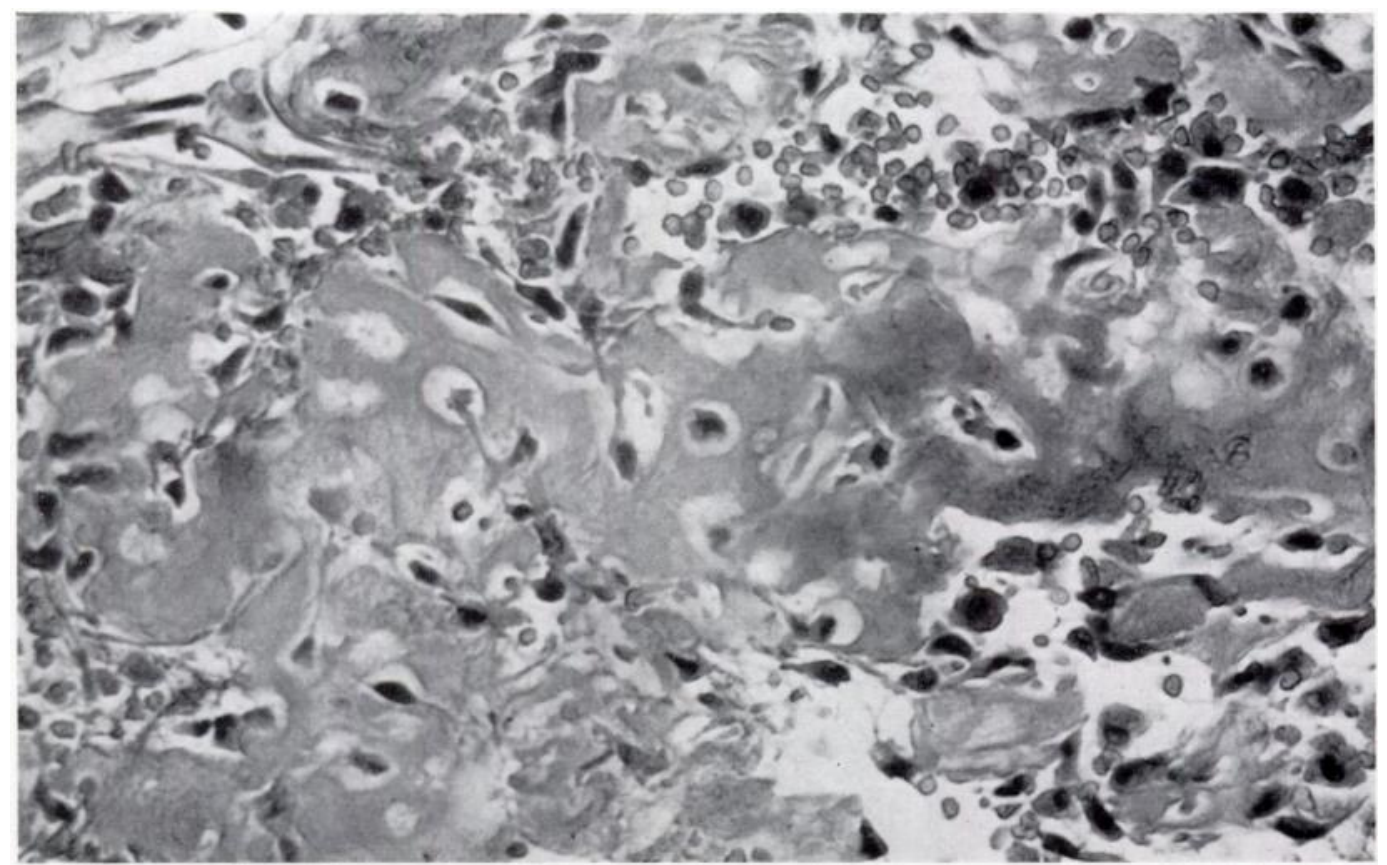

FiG. 19

Case 8. Figure 17-Photomicrograph of a giant-cell tumour of the sacrum. (Haematoxylin and eosin, $\times 400$.) Figure 18-The residual tumour of the sacrum (autopsy material). The pattern of small polyhedral and spindle cells with islets of cartilage differentiation resembles mesenchymal chondrosarcoma. (Haematoxylin and eosin, $\times 400$.) Figure 19-Part of the residual tumour invading the fifth lumbar vertebra. Here there is an area of osteoid formation by tumour which resembles osteosarcoma. (Haematoxylin and eosin, $\times 400$.) 
COMPLICATIONS

Complications included recurrence, metastases, pathological fractures, non-union of grafts, infection, severe haemorrhage and death.

Recurrence-The overall recurrence rate of 33 per cent compared closely with that of Goldenberg et al. (1970). Of the seventeen recurrences, five were malignant changes of previously typical tumours.

TABLE III

Malignant Tumours

\begin{tabular}{|c|c|c|c|c|c|c|}
\hline $\begin{array}{c}\text { Case } \\
\text { number }\end{array}$ & $\begin{array}{c}\text { Age at } \\
\text { diagnosis } \\
\text { (years) }\end{array}$ & Site & Type & $\begin{array}{l}\text { Primary } \\
\text { treatment }\end{array}$ & $\begin{array}{l}\text { Secondary } \\
\text { treatment }\end{array}$ & Result \\
\hline 1 & 48 & Tibia, upper end & $\mathbf{S}$ & RT & Amputation & $\begin{array}{l}\text { Died of carcinoma } \\
\text { of bronchus }\end{array}$ \\
\hline 2 & 34 & Femur, lower end & $\mathbf{S}$ & RT & $\begin{array}{l}\text { Amputation. } \\
\text { Block dissection } \\
\text { of glands }\end{array}$ & Died of tumour \\
\hline 3 & 24 & Humerus, upper end & $\mathbf{P}$ & RT & $\begin{array}{l}\text { Amputation. } \\
\text { Lobectomy }\end{array}$ & Died of tumour \\
\hline 4 & 34 & Tibia, upper end & $\mathbf{S}$ & $\mathrm{C}+\mathrm{RT}$ & Amputation & Alive and well \\
\hline 5 & 42 & Sacrum & $S$ & RT & RT to chest & Died of tumour \\
\hline 6 & 35 & Femur, lower end & $\mathbf{P}$ & $\mathbf{C}+\mathbf{G}+\mathbf{R T}$ & Amputation & Alive and well \\
\hline 7 & 41 & Femur, shaft & $\mathbf{P}$ & $\mathrm{C}+\mathrm{G}$ & $\begin{array}{l}\text { Amputation. } \\
\text { RT to pelvis }\end{array}$ & Died of tumour \\
\hline 8 & 30 & Sacrum & E & RT & $\begin{array}{c}\text { RT. } \\
\text { Chemotherapy }\end{array}$ & Died of tumour \\
\hline
\end{tabular}

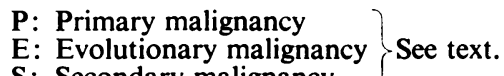
RT: Radiotherapy.
S: Secondary malignancy
C: Curettage.
G: Graft.

Metastases-Pulmonary metastases occurred in three patients, two of whom had been initially treated by radiotherapy and the third by curettage and graft. An unsuccessful left dorsal lobectomy was done on one occasion.

Pathological fractures-Seven patients presented with pathological fractures. Two other patients developed fractures after radiotherapy, a recognised hazard of this form of treatment (Coley 1960).

Non-union, infection and haemorrhage-Of three patients treated by curettage and graft, one developed deep infection, a second had infection and non-union of the graft, and the third non-union and considerable haemorrhage leading to anaemia. Although all three patients ultimately had amputation the complication was the indication in only one.

Death-Ten patients have died, five because of the tumour or its treatment; three died of pulmonary metastases and two of local complications. Both the sacral tumours were fatal, one because of local effects and the other because of pulmonary metastases.

Of the other five, one had a neoplasm in the chest with secondary deposits in the face and neck which was probably a carcinoma of the bronchus. The remainder died of cardiovascular disease.

\section{DISCUSSION}

Diagnosis-The clinical features of the tumours were not diagnostic. In particular "egg-shell crackling"- a late sign-was not recorded. 
Nearly all the tumours had characteristic radiographic features. They all occurred in skeletally mature patients, and all but one of those in long bones were in the expanded extremities. The radiological diagnosis of a giant-cell tumour must always be in doubt if it occurs in a skeletally immature patient or not generally within the epiphysial region (Dahlin et al. 1970).

In our records the macroscopic appearances of the tumour were often poorly described and the surgeon can greatly assist the pathologist by carefully noting the gross features of the tumour at operation. Of importance are the depth at which the tumour is found, the degreo - if any - of penetration of soft tissue, and the wall, colour, vascularity and consistency of the tumour. A tumour consisting chiefly of solid white fleshy material is more likely to be a sarcoma, in which event the plan of treatment will require revision.

Of the various other lesions that contain giant cells, the "brown tumour" in particular may prove impossible to distinguish histologically from giant-cell tumour. Radiographs of the hands and biochemical tests are necessary to confirm the diagnosis of hyperparathyroidism. Prognosis-There was no constant relationship between the severity and duration of symptoms, and the degree of aggressiveness of the tumours. Severe pain of short duration did not necessarily indicate a malignant tumour. In all but one patient-who presented with a six-week history of sciatica-the duration of pain in malignant tumours was at least four months.

The presence of fractures was not an unfavourable prognostic sign. On the other hand, tumours situated in unusual sites with an ill-defined edge to the translucent zone or with rapid extension were aggressive.

Histological grading of tumours was not a reliable guide either to prognosis or treatment, and the procedure was abandoned. Mitotic figures were constantly found in the stroma cells. Their numbers were usually low, but occasionally sufficiently high to perturb the histologist. Up to the present time, however, this feature when taken alone has not proved to be a reliable index of tumour behaviour (Price 1971).

The term evolutionary malignancy was used to describe one typical tumour that progressed to a mixed malignant form twelve months after radiotherapy. Because a radiation sarcoma usually occurs after a relatively long latent period free from symptoms (Cruz, Coley and Stewart 1957), this malignant change was considered to be a natural evolution of the tumour. It is of interest that this tumour was one of the two in the sacrum, in which the histological sections showed many large giant cells, and for which the prognosis was poor. Mnaymneh, Dudley and Mnaymneh (1964), Dahlin et al. (1970) and Goldenberg et al. (1970) also found that sacral tumours had a poor prognosis.

\section{PRIMARY TREATMENT}

Amputation-Of the three amputations, one was done on a man of seventy-seven years with advanced osteoarthrosis of the knee, for a tumour thought to be malignant. When there exist such factors as the advanced age of the patient, ominous appearance of the tumour, or previous joint disease, amputation may be expedient but otherwise it has little place in the primary treatment.

Radiotherapy-In comparing the results of radiotherapy with those of surgery it is only fair to consider tumours in sites amenable to surgical treatment. In long bones there were four recurrences ( 50 per cent), two being malignant changes of typical tumours. The deaths of two patients with long bone tumours were caused by the effects of radiotherapy. Megavoltage therapy has only been used here for five years and cannot be accurately assessed after this period. Nevertheless, the results of radiotherapy indicate that its use should be confined to tumours in surgically inaccessible sites.

As regards dosage, Hale (1971) has suggested a single course of 5,000 r of megavoltage irradiation given over a period of five to six weeks. 


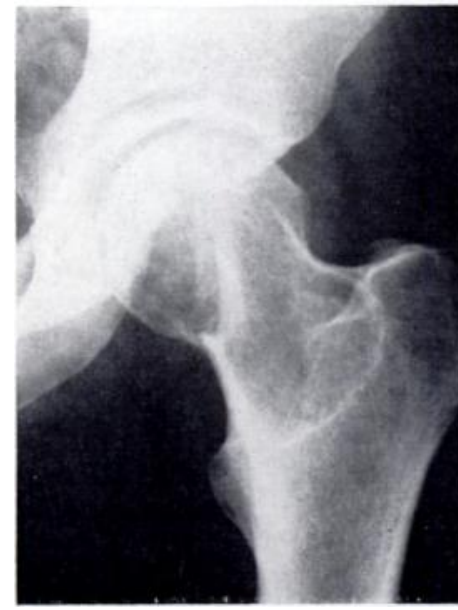

FIG. 20

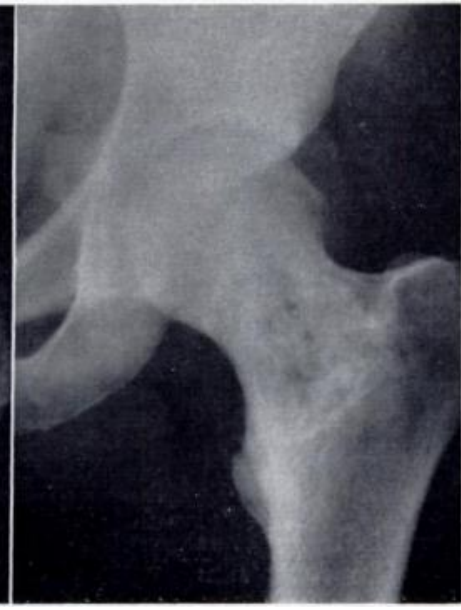

FIG. 21

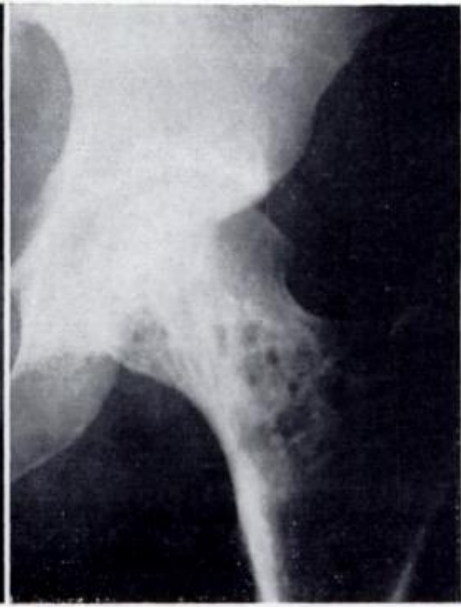

FIG. 22

Case 11. Figure 20-Radiograph of a tumour in the upper end of the femur. Figure 21-Four years after curettage and graft. Figure 22-Fifteen years after curettage and graft. There was excellent movement in the hip clinically.

Resection-There were no recurrences after resection. Ideal for tumours in suitable sites, such as the upper fibula, lower ulna, the radius and some tumours of the ilium, it is essential for tumours that have extended into the soft tissues, for which curettage would be inadequate. If the tumour is adjacent to a large joint and has not perforated the bone, the benefits of resection must be considered against the interference with function of the joint.

Curettage and graft-Although the recurrence rate of 45 per cent was higher than that of the two recent large series, none of the recurrences was malignant. Subsequent treatment by resection or amputation was successful.

Five patients with pathological fractures were treated by curettage and graft, and in only one did the tumour recur. Therefore, in planning treatment, the presence of a pathological fracture does not of itself contra-indicate curettage and graft.

Surgical technique is important. A sufficiently large amount of overlying bone must be removed to allow thorough evacuation of the contents, care being taken to avoid seeding with tumour cells by covering all soft tissues with towels, by adequate irrigation of the cavity, and by a complete change of gowns, gloves, towels and instruments before reconstruction and closure (Riley, Hartmann and Robinson 1967). Although Dahlin et al. (1970) found that cautery after curettage or excision did not influence the recurrence rate, in this series cautery was worth while.

If the cavity cannot be filled by autogenous bone, it should be supplemented. Burwell (1969) concluded that freeze-dried homologous cancellous bone sterilised by irradiation was probably the best bank bone for clinical use, and Roaf and Hancox (1963) reported the successful use of heterogenous deproteinised bone to fill defects in bone.

It is recommended that careful curettage and graft be strongly considered for every possible case, especially when the tumour is near an important joint in a young patient, when it is of moderate size and if it has not penetrated the soft tissues (Figs. 20 to 22).

\section{SECONDARY TREATMENT}

No recurrence of a typical tumour in a long bone that appeared within two years of primary treatment was malignant. Such a recurrence can safely be treated by resection or, if small, by a second curettage and graft without biopsy. 
However, if a recurrence appears more than five years after primary treatment, it must always cause suspicion. Biopsy is necessary; because if the tumour has not changed histologically resection is satisfactory, but malignant change-usually to a fibrosarcomanecessitates amputation at the appropriate level, the prognosis being poor.

\section{SUMMARY}

1. Fifty-five giant-cell tumours of bone are described in fifty-two patients of whom thirty-five were women. The highest incidence was in the third and fourth decades.

2. The tumours were characteristic radiologically: they all occurred in skeletally mature patients, and chiefly in the expanded extremities of long bones.

3. Histological grading was not done, the tumours being designated typical or malignant.

4. Curettage and graft, resection, radiotherapy and amputation were the basic forms of treatment. Amputation has an occasional place in primary treatment and radiotherapy should be confined to tumours in surgically inaccessible sites.

5. Resection is the method of choice for tumours in suitable sites, such as the upper end of the fibula; careful curettage and grafting should be used to preserve the function of a large joint. 6. Recurrences within two years should be treated by limited resection without preliminary biopsy. Late recurrences must have a biopsy taken to establish the diagnosis before planning treatment.

I wish to thank the orthopaedic surgeons of the Bristol Clinical Area and elsewhere for allowing me access to their cases. The staff of the Department of Medical Illustration of the Bristol Royal Infirmary and of the Bristol Bone Tumour Registry kindly prepared the illustrations. I am indebted to Dr C. H. G. Price, not only for collection of the case material, but also for his advice and criticism. Finally, I am grateful to $\mathrm{Mr} \mathrm{A}$. L. Eyre-Brook for his constant help and encouragement. The Bristol Bone Tumour Registry is supported by the British Empire Cancer Campaign and the University of Bristol Cancer Research Fund.

\section{REFERENCES}

Burwell, R. G. (1969): The Fate of Bone Grafts. In Recent Advances in Orthopaedics, p. 115. Edited by A. Graham Apley. London: J. \& A. Churchill Ltd.

Coley, B. L. (1960): Neoplasms of Bone and Related Conditions. Etiology, Pathogenesis, Diagnosis, and Treatment. Second edition, p. 196. New York: Paul B. Hoeber, Inc.

Cruz, M., Coley, B. L., and Stewart, F. W. (1957): Postradiation Bone Sarcoma. Report of eleven cases. Cancer, 10, 72.

Dahlin, D. C., Cupps, R. E., and Johnson, E. W. (1970): Giant-cell Tumor: A Study of 195 Cases. Cancer, 25, 1061 .

DYKe, S. C. (1931): Metastasis of the "Benign" Giant-cell Tumour of Bone (Osteoclastoma). Journal of Pathology and Bacteriology, 34, 259.

ElLIS, F. (1949): Treatment of Osteoclastoma by Radiation. Journal of Bone and Joint Surgery, 31-B, 268.

Eyre-Brook, A. L. (1956): Discussion: Giant Cell Tumour of Bone and Related Conditions. Proceedings of the Royal Society of Medicine, 49, 409.

Finch, E. F., and Gleave, H. H. (1926): A Case of Osteoclastoma (Myeloid Sarcoma, Benign Giant Cell Tumour) with Pulmonary Metastasis. Journal of Pathology and Bacteriology, 29, 399.

Goldenberg, R. R., Campbell, C. J., and Bonfiglio, M. (1970): Giant-cell Tumor of Bone. An Analysis of Two hundred and eighteen Cases. Journal of Bone and Joint Surgery, 52-A, 619.

GoldiNG, C. (1966): Radiology and Orthopaedic Surgery. Journal of Bone and Joint Surgery, 48-B, 320.

Hale, B. T. (1971): Personal communication.

JAFFE, H. L. (1953): Giant-cell Tumour (Osteoclastoma) of Bone: Its Pathologic Delimitation and the Inherent Clinical Implications. Annais of the Royal College of Surgeons of England, 13, 343.

Jaffe, H. L., Lichtenstein, L., and Portis, R. B. (1940): Giant Cell Tumor of Bone. Its Pathologic Appearance, Grading, Supposed Variants and Treatment. Archives of Pathology, 30, 993.

Jewell, J. H., and Bush, L. F. (1964): "Benign" Giant-cell Tumor of Bone with a Solitary Pulmonary Metastasis. A Case Report. Journal of Bone and Joint Surgery, 46-A, 848. 
Mnaymneh, W. A., Dudley, H. R., and Mnaymneh, L. G. (1964): Giant-Cell Tumor of Bone. An Analysis and Follow-up Study of the Forty-one Cases Observed at the Massachusetts General Hospital, between 1925 and 1960. Journal of Bone and Joint Surgery, 46-A, 63.

Murphy, W. R., and Ackerman, L. V. (1956): Benign and Malignant Giant-Cell Tumors of Bone. A ClinicalPathological Evaluation of Thirty-one Cases. Cancer, 9, 317.

Price, C. H. G. (1971): Personal communication.

Prossor, T. M. (1949): Treatment of Giant-Cell Tumours of Bone. With a Review of Twenty-five Cases. Journal of Bone and Joint Surgery, 31-B, 241.

Riley, L. H., Jun., Hartmann, W. H., and Robinson, R. A. (1967): Soft-Tissue Recurrence of Giant-Cell Tumor of Bone after Irradiation and Excision. Journal of Bone and Joint Surgery, 49-A, 365.

Roaf, R., and Hancox, N. (1963): Fate of Heterogenous Deproteinised Bone Implants. Journal of Bone and Joint Surgery, 45-B, 617.

Thomson, A. D., and Turner-Warwick, R. T. (1955): Skeletal Sarcomata and Giant-Cell Tumour. Journal of Bone and Joint Surgery, 37-B, 266.

Wearne, W. M. (1968): Giant-Cell Tumour of Bone. Journal of Bone and Joint Surgery, 50-B, 676.

WindeYer, B. W., and Woodyatr, P. B. (1949): Osteoclastoma. A Study of Thirty-eight Cases. Journal of Bone and Joint Surgery, 31-B, 252.

VOL. 54 B, NO. 2, MAY 1972 